\title{
Issues of creating a new cadre of doctors for rural India
}

\section{Jayakrishnan Thayyil, Mathummal Cherumanalil Jeeja ${ }^{1}$}

Departments of Community Medicine, and ${ }^{1}$ Pharmacology, Government Medical College, Calicut, Kerala, India

Address for the Correspondence:

Dr. T. Jayakrishnan, Department of Community Medicine, Government Medical College, Calicut, Kerala - 673 008, India. E-mail: drjayakrishnant@ yahoo.com

\begin{tabular}{|l|}
\hline Access this article online \\
\hline Website: www.ijmedph.org \\
\hline DOI: 10.4103/2230-8598.109305 \\
\hline Quick response code: \\
\hline
\end{tabular}

'Health gaps between countries and among social groups within countries have widened'. Health is a basic need of a human being and access to health is a basic human right. Article 47 of the Indian Constitution enjoins the State to improve the standard of Public Health, as it is one of its primary duties. India, forms $17 \%$ of the global population and accounts for $20 \%$ of the total global disease burden. There are pronounced disparities existing between the rural and urban areas, as indicated by the infant mortality rates. Eighty-two percent are residing in villages. Seventy-four percent of the doctors live in urban areas, serving only $28 \%$ of the population. The people in rural areas are still unable to access the services of doctors. In this scenario the Ministry of Health $(\mathrm{MOH})$ Government of India (GOI) announced the start of a new course, to create a cadre of rural doctors. The article will look at the shortfalls in the rural health of India as well as region- and statewise disparities in health status, health infrastructure, and manpower availability and the study was conducted by a literature review of government reports and published articles. There exist gross disparities between rural and urban areas due to negligence of the rulers. Even after initiation of the National Rural Health Mission (NRHM) greater than two-thirds of the funds flow to the urban areas/secondary care. The population based on the 2001 census, shows a shortfall in the rural health infrastructure; Community Health Centers $(\mathrm{CHC})-68 \%$, Primary Health Centers $(\mathrm{PHC})-$ $31 \%$, and Subcenters $-(\mathrm{SC})-29 \%$. The solution by creating a new cadre of doctors without improving facilities in the rural areas or without an equitable distribution of resources is unethical. The scarcity of health manpower in rural areas of India was due to skewed prioritization and distribution of resources. This can be corrected by reversing the urban centric planning and bringing equity in social development.

Key words: Access to healthcare, health gap, health manpower, rural healthcare

\section{INTRODUCTION}

As recommended by the National Rural Health Mission (NRHM) task force for medical education ${ }^{[1]}$ and proposed by the study group headed by GP Dutta, the Ministry of Health and Family Welfare, (MOH and FW) and the Medical Council of India (MCI) has decided to start an 'updated alternate model of the medical education course, for creating a new cadre of doctors catering to the rural areas. The course is to be named the 'Bachelor's Degree in Rural Health Care' (BRHC). The duration of the course will be 3.5 years and it will include six months of internship. The candidates will be recruited from among those passing the senior secondary examination with chemistry, botany, and zoology, from schools in the notified rural areas. The curriculum is being worked out by the MCI. After graduating, the candidate is expected to go back and serve the rural community from which she or he has come. The degree will be registered by the MCI in a separate schedule. ${ }^{[2]}$

The article was based on the study done by a detailed literature review of the issues related to this subject, a review of the shortfalls in the rural health of India, as well as region- and statewise disparities in health status, health infrastructure, and manpower availability.

Health is a basic need of a human being and access to healthcare a basic human right. Our country 
has always recognized this fundamental claim of the citizenry. Article 47 of the Constitution enjoins the State to improve the standard of Public Health, as it is one of its primary duties. In broad conceptual terms, India has always been committed to comprehensive healthcare for all. In truth, the government never spelt out what constituted 'comprehensive healthcare.' There was little systematic progress toward a standardized and sustainable health system. ${ }^{[1]}$

Over the five decades since independence, the overall state of health in the country has improved. The trend over time of basic health indicators reveals this clearly: However, despite this improvement, the general health indices in the country are below average for developing countries, and are also way below socially acceptable levels. With $17 \%$ of the global population, the country accounts for $20 \%$ of the total global disease burden, $23 \%$ child deaths, 20\% maternal deaths, and 30\% tuberculosis (TB) cases. ${ }^{[1]}$ India continues to bear a disproportionate portion of the global burden of pre-transition communicable diseases - the estimated prevalence of TB, malaria, and typhoid was 131, 134, and 73 per one lakh population. ${ }^{[3]}$

\section{Regional variation in the health status}

More significant than all these macro-level statistics is the fact that the average health indicators hide a wide range of variations between different parts of the country. Infant mortality rate (IMR) is considered to be a very good social development indicator. As per the sample registration system, (SRS) 2007 reports that the IMR in the Indian urban area is 37 compared to 61 in the rural areas. IMR in Madhya Pradesh is 82 and in Orissa 83 , which is more than eight times higher than that in Kerala 11. There is also a pronounced disparity between rural and urban areas - in Andhra Pradesh, the rural IMR is 67 compared to 33 in the urban areas; and in Karnataka the rural IMR is 61 as against 24 in the urban areas. ${ }^{[1]}$ The NFHS III reports that in rural areas the IMR shows an increasing trend. The high degree of variation of health indices is itself a reflection of the high variance in the availability of healthcare services in different parts of the country.

Although rural people account for nearly three-fourths of the country's population, they are denied even the basic medical care required for treating the common and preventable medical problems that constitute $80 \%$ of all medical conditions. The primary reason for this difference in the availability of primary healthcare services is the human resource crisis. There is an acute shortage of medical professionals on the one hand due to iniquitous distribution. ${ }^{[4]}$

On the basis of the health status of the population, and the existing capacity of the health service delivery system, the states within the country can be divided into four main groups. The group with the highest health standards (Kerala and Tamil Nadu) covers $9.1 \%$ of the population; and at the other end of the spectrum, the group with the lowest health standards (Assam, Bihar, and Jharkhand) covers $13.1 \%$ of the population. ${ }^{[1]}$ The former states achieved this status by social measures and political will, and equity in distribution of health resources. ${ }^{[3]}$

\section{Public healthcare system}

The primary healthcare infrastructure in the country is a three-tier system with Subcenters (SC) $(n=146,036)$, Primary
Health Centers (PHC) $(n=23,458)$, and Community Health Centers $(\mathrm{CHCs})(n=4,276)$. The Subcenters are the most peripheral and the first contact point between the healthcare system and the community. ${ }^{[5]}$ The $\mathrm{PHC}$ is the first contact point between the village community and the certified medical officer. A CHC, with specialized services in the form of surgeons, obstetricians, gynecologists, physicians, and pediatricians, is a referral unit for PHCs.

The public sector provides $18 \%$ of the total outpatient care, $44 \%$ of the inpatient care, $54 \%$ of the institutional deliveries, $60 \%$ of the prenatal care visits, and $90 \%$ of the immunization. ${ }^{[1]}$ The private sector provides $58 \%$ of the hospitals, $29 \%$ of the beds in the hospitals, and $81 \%$ of the doctors. ${ }^{[1]}$ The quantum of health services it provides is large, but is of poor and uneven quality. The private sector has wide variations; at one end providing world class services beyond the capacity of most Indians and at the other end poor quality unregulated/underqualified..$^{[3]}$

\section{Health manpower}

The number of trained medical practitioners in the country is as high as 1.4 million, including 0.7 million graduate allopaths. The number of allopathic doctors in urban areas is four times that in the rural areas. However, the rural areas are still unable to access the services of the allopaths. Seventy four percent of the graduate doctors live in urban areas, serving only $28 \%$ of the national population, while the rural population remains largely unserved, not due to scarcity, but mainly due to non-equity in distribution. Due to this the rural population has to depend on the services of the 'quacks' whose services are rampant in such areas.

The number of allopathic doctors possessing recognized medical qualifications and registered with the state medical councils for the years 2007 and 2008, were 708,043 and 725,190, respectively. Out of this only 24,375 were employed in the public sector (3.4\%) and the rest were working in private care, mostly in the urban areas ${ }^{[6]}$ In other words, the total doctor population ratio was 1:1,676 (public + private sector combined) and in public sector the ratio was only 1:34,000. One of the causes for scarcity of doctors in the rural public sector was not reluctance, but insufficient posts. Therefore, for getting adequate service to people, the State Health Ministry had to create more posts of doctors in the public health facilities. Contrary to this, most of the posts created under NRHM were for a contract period of one year, which most of the doctors would not stick to.

As on March, 2008, the overall shortfall for doctors at PHCs was $19 \%$ of the total requirement. In the absence of doctors the health workers had to give primary healthcare services, which were also deficient, which clearly showed the interest of our rulers in rural health issues. The shortfalls were as follows: In the posts of health worker females (HW-F)/Auxiliary nurse midwife (ANM) it was $12.4 \%$, for health worker males (HW-M) it was $56.8 \%$, in the case of Health Assistant (Female)/LHV the shortfall was 29.1\%, and in that of Health Assistant (Male) it was 39.1\%. ${ }^{[5]}$

\section{Manpower shortage in rural areas}

The created posts are insufficient to meet the needs. Moreover, even in the created posts, large proportions remain vacant, especially in remote areas. As per the available data, overall about $13 \%$ of the 
doctors at PHCs and $51.6 \%$ of the sanctioned posts of specialists at $\mathrm{CHCs}$ are vacant, which is clearly an alarming situation.

As on March, 2008, 12.4\% of the PHCs were without a doctor, about $37.8 \%$ were without a laboratory technician, and $16.3 \%$ were without a pharmacist. In Bihar, 1,243 PHCs are functioning without Medical Officers. ${ }^{[5]}$ It is because of this large shortfall of doctors that the health centers are unable to deliver the larger part of the Primary Healthcare package. Therefore, the governments need to have a political will to fill the existing vacancy. At the same time as a patchwork, the fresh unexperienced junior doctors have been asked to work in rural PHCs, as a part of compulsory rural service. Compulsion fills up vacancies much more at the apparent level than at the real level. It also provides a poor quality person for these jobs, with very short-term commitments to work there. After all, one can force a horse to the water, but one cannot make it drink. ${ }^{[6]}$ These arrangements also deny the marginalized rural people from getting appropriate care. The idea of a new course is to encourage students from rural areas to take up medicine and then provide services in their local areas. If these graduates cannot perform surgical procedures, how will they manage road traffic accidents and surgical emergencies?

\section{Infrastructure shortage}

Even after 60 years of acquiring independence, there is an acute shortage of physical infrastructure in the public health sector. As per the statistics available on March 2008, based on the 2001 Population Census, the shortfall in the rural health infrastructure is of 20,486 Subcenters, 4,477 PHCs, and 2,337 CHCs. ${ }^{[5]}$ The deficiencies for different levels of service centers in the year 2004, had been as follows: $\mathrm{CHC}-68 \%$; $\mathrm{PHC}-31 \%$; SC $-29 \% .^{[2]}$ The shortage is evidently more in the remote rural areas where there is need for services; and without health centers how can health services be delivered?

Out of the total 23,458 PHCs in India, 1,212 (5\%) have no buildings. As per our country norms, one PHC has to cater service to a population of 30,000 . In 13 states one $\mathrm{PHC}$ has to cater to a population of more than 30000, and it is worse in Bihar, Jharkhand, and West Bengal. During the period of the Eleventh plan, the increase in the number of PHCs has been only $4 \%$ and that of $\mathrm{CHCs}$ has been $5 \%$, which does not consider the need or equity. ${ }^{[3]}$ Without a health center in the geographical area, how can we ensure accessibility of health service to the rural area? Even under the NRHM scheme the newly constructed hospitals are mostly urban centered (70:30).

\section{Reluctance of doctors to work in rural areas}

It is generally stated that most doctors who have grown up and been trained in an urban setup are reluctant to work in a rural setup. The few with a rural background acquire an urban mindset in the course of their training, which is focused around a tertiary care hospital. When a doctor is posted in a rural area, the minimum expectation is for a residential accommodation of reasonable quality, with water and electricity connection. As per the available statistics $27 \%$ of the PHCs in Jharkhand have no road accessibility and $34.5 \%$ of the PHCs have no drinking water available. Forty-five percent of the PHCs in Assam have no electricity supply and in
Bihar $78 \%$ of the PHCs have no phone connections. ${ }^{\left[{ }^{[}\right]}$How can we ask our young graduates to take over charge of such PHCs? The solution lies in improving road communication with villages; making the basic amenities of life, including quality education for children, available and within reach of the rural areas, along with evolving a fair system of posting and transfer. ${ }^{[7]}$

To attract young doctors to rural areas and enable such health sector functionaries to cope with the social and infrastructural shortcomings, the task force has given suggestions, which are neglected by the authorities. One method is to offer some monetary compensation by way of a 'hardship allowance/rural allowance' of at least Rs. 3000/- per month. The second recommendation is that $50 \%$ of the postgraduate seats in medical colleges be reserved for government doctors who have served in rural areas for over five years. ${ }^{[1]}$ Such a provision would make over 5000 postgraduate seats available to government doctors, and this would be a significant incentive for young doctors serving in rural areas.

\section{Medical education}

There are about 300 medical colleges, with an annual admission of about 34,000 functioning in our country. ${ }^{[8]}$ They are functioning without considering the regional distribution or need of the people. MBBS seats of $66.6 \%$ and $63 \%$ of the medical colleges are functioning in six southern states. In contrast to this, the backward Empowerd Action Group (EAG) states have got only 17.5\% seats, and the nine North eastern states have only $2.5 \%$ seats. These states have an urgent need and scarcity of doctors. Instead of starting the BRHC courses in those 300 backward districts where there is no existing medical college, the government can start new rural medical colleges in the backward districts of the states, with rural reservations, by utilizing the facilities of the existing district hospitals. The government could grant a waiver or high concession in fees to those who join the MBBS course, under a bond, with a surety that they would serve in the rural area for three years after graduation. ${ }^{[9]}$ Likewise, doctors starting a hospital in rural areas should be given financial and other incentives. More hospitals in rural areas will automatically mean more jobs for doctors there. ${ }^{[0]}$

As per the MCI spokespersons 'the model would be piloted in a few government institutions. If the trial proved to be a success, the model would be extended to the private sector'. This gave us a clue that in the case of BRHC, the interest was not in serving the poor, but in privatization and commercialization, as in the case of the MBBS course.

\section{Issues}

Do we need another substandard undergraduate degree to help our rural population because most of our trained doctors are unwilling to serve them?

Can we make the medical rural service more attractive to motivate young doctors to join in Public Health Service?

The attempt is to segregate medical services at three levels - the first is the level of primary healthcare services that can be delivered with an optimal level of competence by the short-course health practitioner, exclusively for rural areas, the second category is of the balance of 
the medical conditions, where only the graduate MBBS doctor will be licensed to deliver services; and the third is the domain of the specialist with postgraduate qualifications; which is for urban areas, is injustice.

The training of these rural healthcare practitioners will be a major area of concern. It is doubtful as to how overworked, poorly staffed, ill-equipped district hospitals, which cater to thousands of patients and exist in more than half the districts of the country, can become training grounds for healthcare practitioners. ${ }^{[9]}$

Is the duration of training of three plus years adequate to practice in the rural setting, which is, as it is, more demanding than urban practice since often there is no one to help and nowhere to refer patients?

A legacy from the British times, we had the Licentiate Medical Practitioners (LMP), who had to undergo a three-year course. Only then were they authorized to practice over the entire range of medical conditions. With the intention of improving the standard of medical services in the country, the cadre was discontinued after 1964. As per the IMC Act 1956, section (12) (b), the minimum qualification for practicing modern medicine in India is a 4.5 year course, followed by one year of internship.

They will not be allowed to perform surgical procedures. They will be of no use if they cannot deliver emergency obstetric care.

How can we be sure that candidates for the BRHC course selected from a rural background will serve rural areas after qualification?

At the end of five years, these practitioners would be free to migrate and practice in cities or seek postgraduate seats, as they would then be deemed to be equal to MBBS graduates. Who will monitor the quality of work of the BRHC graduates? Thus, it becomes government sponsored quackery.

\section{CONCLUSION}

The move to create the BRHC course is a retrograde step that can dilute the high standards associated with Indian healthcare professionals..$^{\left[{ }^{[9]}\right.}$ The scarcity of health manpower in the rural areas of India is due to skewed prioritization and distribution of resources. This can be corrected by reversing the urban centric planning and bringing equity in social development.

\section{REFERENCES}

1. Report: Task Force on Medical Education for the National Rural Health Mission [Internet]. New Delhi: Ministry of Health and Family Welfare. Government of India. Available from: http://www.mohfw.nic.in/NRHM/ Documents/Task_Group_Medical_Education.pdf. [Last cited on 2010 Oct 10].

2. Ananthakrishnan N. Proposed bachelor's degree in Rural Health Care: An unmixed blessing for the rural population or for the graduate or neither? Natl Med J India 2010;23:250-1.

3. Jayakrishnan T. BRHC; The disease and treatment. Sasthragathi 2010;10:33-40.

4. Ramachandran. Missing Doctors. Frontline [Inter net]. 2010;27:[about 7p]. Available from: http://www.flonnet.com/fl2704/ stories/20100226270411400.htm. [Last cited on 2010 Apr 30].

5. Rural Health Infra structure. In Bulletin on Rural Health statistics in India. 2008. India: Ministry of health and Family welfare, Government of India; 2009. p. 19-54.

6. Varghese J. The new rural doctor: Qualified quack or appropriate healthcare provider? Indian J Med Ethics 2010;7:70-2.

7. Ghosh K. Bachelor of Rural Health Care: Cutting the root and watering the stem! Natl Med J India 2010;23:250.

8. Human resources in health sector. National Health Profile (NHP) of India 2008 [Internet]. Central Bureau of health Intelligence. $\mathrm{MOH}$ and FW. New Delhi: Government of India; 2009. p. 13745. Available from: http:// cbhidghs.nic.in/writereaddata/mainlinkFile/File1135.pdf [Last cited on 2012 Oct 9].

9. Garg S, Singh R, Grover M. Bachelor of rural health care: Do we need another cadre of health practioner for rural areas? Natl Med J India 2011;24:35-7.

How to cite this article: Thayyil J, Jeeja MC. Issues of creating a new cadre of doctors for rural India. Int J Med Public Health 2013;3:8-11.

Source of Support: Nil, Conflict of Interest: Both the authors are working as faculty in medical college under public sector. 